๑ Entomologica Fennica. 19 September 2003

\title{
New or little known Palaearctic species of Platygastrinae (Hymenoptera: Platygastridae)
}

\author{
Peter Neerup Buhl
}

Buhl, P. N. 2003: New or little known Palaearctic species of Platygastrinae (Hymenoptera: Platygastridae). — Entomol. Fennica 14: 109-117.

Seven species new to science are described and their affinities discussed, viz. Platygaster baezi (Canary Islands), P. fennica (Finland and Sweden), P. koponeni (Finland and Denmark), P. martikaineni (Finland and Denmark), $P$. marttii (Finland), Synopeas koponeni (Canary Islands), and S. suomiana (Finland). The hitherto unknown female of Platygaster danielssoni Buhl, 1998, and the hitherto unknown male of P. tenerifensis Buhl, 2001 are described.

Peter Neerup Buhl, Troldhфjvej 3, DK-3310 Ølsted, Denmark; E-mail: pnbuhl@zmuc.ku.dk

Received 30 May 2002, accepted 5 March 2003

\section{Introduction}

Among about 530 Finnish specimens of Platygastridae, mostly collected by Martti Koponen and Petri Martikainen, at least five new species of Platygastrinae were identified, collected in southern and central parts of the country. A total of 60 more species could be identified from the samples. A list of these is given in Buhl \& Koponen (2003a).

Among ca. 350 specimens of Platygastridae from Madeira and the Canary Islands, mostly collected by Martti Koponen and Marcos Báez, at least two species were new to science, also described below. A list of the identity of the other specimens is given in Buhl \& Koponen (2003b).

Specimens are mostly deposited in the Department of Applied Biology, University of Helsinki $(\mathrm{DABH})$, the Museo de Ciencias Naturales de Tenerife (TFMC), and the Zoological Museum, University of Copenhagen (ZMUC).

\section{Species}

\section{Platygaster baezi sp. n. (Fig. 1)}

Type material. Holotype Q: Canary Islands, Tenerife, Punta de Teno, 14.XII.1997, M. Báez leg. (TFMC). Paratypes: 2 우 $10^{7}$ same data (one in ZMUC).

Diagnosis. A species with female preapical antennal segments about as long as wide, frons and occiput finely striated, smooth mesoscutum without notauli, and short metasoma with second tergite slightly striated.

Description. Female. Body length $1.0 \mathrm{~mm}$. Colour shiny black, T1 light brownish; A1-A3 and legs yellowish brown; A4-A10, coxae, most of femora, apical half of middle and hind tibiae, and last segment of all tarsi somewhat darker brown.

Head from above (Fig. 1a) 2.0 times as wide as long, fully 1.1 times as wide as mesosoma. 


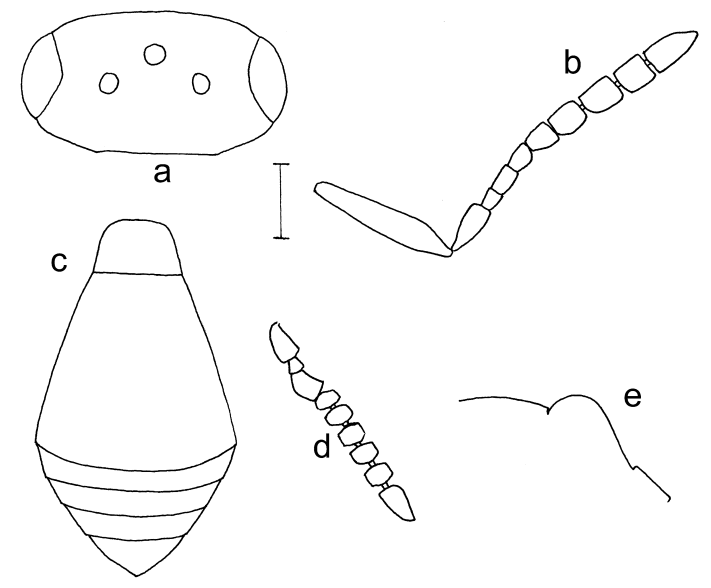

Fig. 1. Platygaster baezi sp. n. - a. Female, head from above. - b. Female, antenna. - c. Female, scutellum and propodeum. $-\mathrm{d}$. Female, metasoma from above. - e. Male, antenna (A2-A10). Scale bar $=0.10 \mathrm{~mm}$.

Occiput densely and rather finely transversely striated all over; vertex faintly reticulate-striate; frons finely transversely striated, smoother medially. $\mathrm{OOL}=\mathrm{LOL}$. Head in frontal view 1.3 times as wide as high. Antenna (Fig. 1b) with A1 0.75 as long as height of head.

Mesosoma 1.3 times as long as wide, very slightly higher than wide. Sides of pronotum finely reticulate-striate with a smooth wide hind margin. Mesoscutum smooth, weakly reticulatecoriaceous antero-laterally, without notauli, almost bare; scuto-scutellar grooves narrow and with few hairs. Mesopleuron smooth. Scutellum (Fig. 1c) evenly convex, hardly above mesoscutum, smooth and almost bare. Metapleuron with rather dense whitish pilosity all over. Propodeal carinae parallel, area between them slightly transverse, smooth and shiny.

Forewing 0.8 times as long as body, 2.4 times as long as wide, clear but with rather distinct hairs on disc except basally; longest marginal cilia about 0.1 width of wing. Hind wing 5.3 times as long as wide, with two frenal hooks; marginal cilia onefourth the width of wing.

Metasoma (Fig. 1d) hardly as long as head and mesosoma combined (14:15), 0.9 times as wide as mesosoma. T1 finely and evenly crenulated. T2 slightly striated in basal foveae to one-third, with a few shorter striae medially. T3-T6 almost smooth; T3-T5 each with a transverse line of

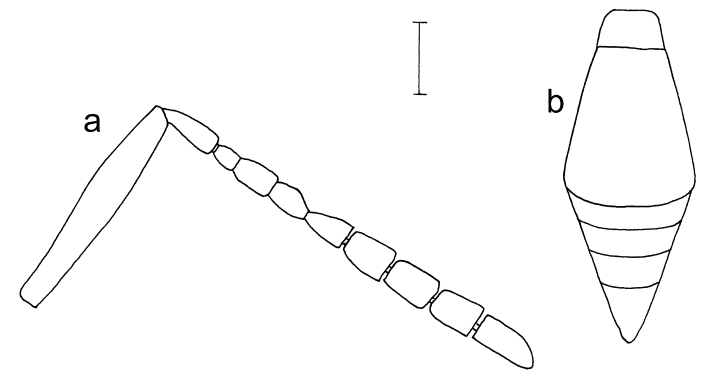

Fig. 2. Platygaster danielssoni Buhl, 1998, female. a. Antenna. - b. Metasoma from above. Scale bar $=$ $0.10 \mathrm{~mm}(\mathrm{a})$ and $0.20 \mathrm{~mm}$ (b).

rather superficially implanted hairs; T6 with scattered hairs.

Male. Body length $0.9 \mathrm{~mm}$. Antenna (Fig. 1e).

Affinities. Runs to $P$. inermis Walker, 1835 in Vlug's (1985) and Buhl's (1999a) keys, but $P$. inermis has scale-like hair-implantations on mesoscutum and female metasoma more pointed than in P. baezi. Of the species described from Spain by Buhl (1999b) somewhat similar to $P$. etsuhoae and $P$. javieri, but the first mentioned species has frons not striated and notauli indicated; the last mentioned has preapical antennal segments more elongate than in P. baezi. In Kieffer's (1926) key $P$. baezi runs to $P$. cecconii Kieffer, 1913 from Italy, but this species has smooth frons, male A4 narrower than rest of flagellum that is widened towards apex, and female metasoma longer than head and mesosoma combined.

\section{Platygaster danielssoni Buhl, 1998 (Fig. 2)}

Material examined. Female: Finland (6774:436), Ta, Nastola 22.VI.1980, M. Koponen leg. (DABH).

Description. The hitherto unknown female: Length $1.7 \mathrm{~mm}$. Antenna (Fig. 2a). Metasoma (Fig. 2b) almost 1.2 times as long as head and mesosoma combined, sculptured as in male. Sternum 2 not convex.

\section{Platygaster fennica sp. n. (Fig. 3)}

Type material. Holotype O: Finland (69077:6026), Sb, Savonranta, 13.VII.-10.VIII.1996, P. Marti- 
kainen leg. Window trap on dead aspen. (DABH). Paratypes (10 + ): 2 same data as holotype; 8 \% same data but 18.VI.-13.VII.1996. (DABH). Additional material. 1 \& Sweden, Sk., Dalby, 14.20.VIII.1998, R. Danielsson leg., yellow pan trap. (In the Museum of Zoology, Lund University, Sweden).

Diagnosis. A species with A1-A3 and legs brightly coloured, frons finely fan-like sculptured and occiput distinctly striate; preapical antennal segments hardly longer than wide; notauli incomplete but distinct; metasoma short, with striated T2 .

Description (female). Body length 1.5-1.6 $\mathrm{mm}$. Colour dark brown, A1-A3 and legs bright yellow; A4-A5, coxae and last segment of tarsi medium brown, A6-A10 dark brown.

Head from above (Fig. 3a) 2.0 times as wide as long, very slightly wider than thorax across tegulae; occiput distinctly and densely but not strongly transversely striated; vertex rounded, finely reticulate-coriaceous, with a few transverse wrinkles between ocelli; frons finely fan-like reticulate-coriaceous. OOL: $\mathrm{LOL}=7: 6$. Head in frontal view 1.25 times as wide as high; antenna (Fig. 3b) with A1 0.9 times as long as height of head.

Mesosoma 1.3 times as long as wide, hardly 1.1 times as high as wide. Sides of pronotum finely longitudinally reticulate-coriaceous except smooth hind margin. Mesoscutum shiny, with partly obliterated reticulation, sparsely hairy; notauli distinct in about posterior two-thirds; mid lobe posteriorly blunt, slightly prolonged; scutoscutellar grooves with numerous whitish hairs. Mesopleuron smooth. Scutellum (Fig. 3c) evenly convex, slightly above level of mesoscutum, smooth except for rather dense hair-implantations. Metapleuron with whitish pilosity all over. Propodeal carinae low and straight, parallel, area between them smooth and shiny, hardly transverse.

Forewing 0.8 times as long as body, 2.6 times as long as wide, almost clear but densely hairy, nearly bare in basal two-fifths; marginal cilia very short. Hind wing 5.0 times as long as wide, with two frenal hooks; marginal cilia one-fifth the width of wing.

Metasoma (Fig. 3d) about 1.0-1.2 times as long as head and mesosoma combined, about as wide as thorax. T1 finely and densely crenulated, with three weak longitudinal carinae. T2 striated

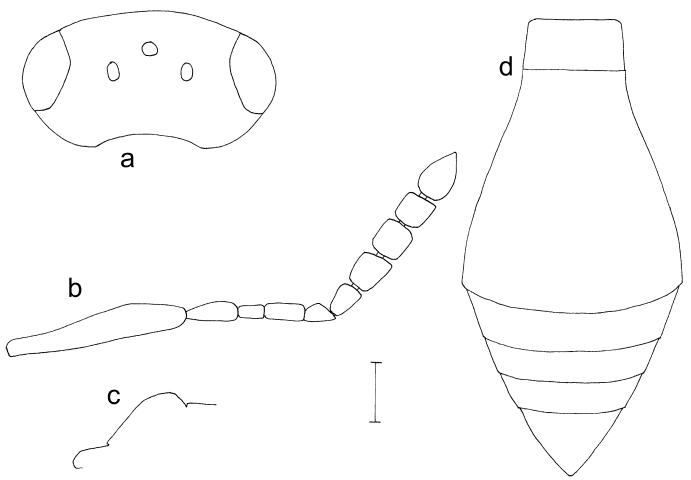

Fig. 3. Platygaster fennica sp. n., female. - a. Head from above. - b. Antenna. - c. Scutellum and propodeum. - d. Metasoma from above. Scale bar = $0.10 \mathrm{~mm}$.

in basal foveae to almost 0.6 of length, between foveae to almost 0.3 of length. T3-T6 smooth, each with a few superficially implanted hairs.

Affinities. Runs to Platygaster ungeri Buhl, 1999 from Denmark in Buhl's (1999a) key, but $P$. ungeri differs from $P$. fennica in numerous details, e.g. it is much darker coloured, it has T2 smooth medially and apical tergites with more distinct hairs, head and antennal measurements slightly different. P. fennica is also similar to Danish P. clavata Buhl, 1994, but this species has A8-A9 transverse, and it has head less transverse, scutellum lower, and mesoscutum smoother than in $P$. fennica . The Finnish specimens of $P$. fennica are very similar, but the single Swedish specimen is slightly aberrant, and it is with a little doubt that I refer it to this species. For example, it has preapical antennal segments slightly transverse, head and mesoscutum stronger sculptured than in types, and hairs of scuto-scutellar groves and of metasoma more distinct.

\section{Platygaster koponeni sp. n. (Fig. 4)}

Type material. Holotype E: Finland (6704:381), N, Nurmijärvi, 3.VIII.1991, M. Koponen leg. (DABH). Paratypes (3 P): Denmark, NEZ, Holte, Ruderhegn 1 O 3.IX.1893, R. W. Schlick leg.; Denmark, NEZ, Jægerspris Nordskov, 1 ㅇ 3.VIII.1986, P. N. Buhl leg.; Denmark, NEZ, Lille Hareskov, 1 E 27.VIII.1993, P. N. Buhl leg. (All in ZMUC). 


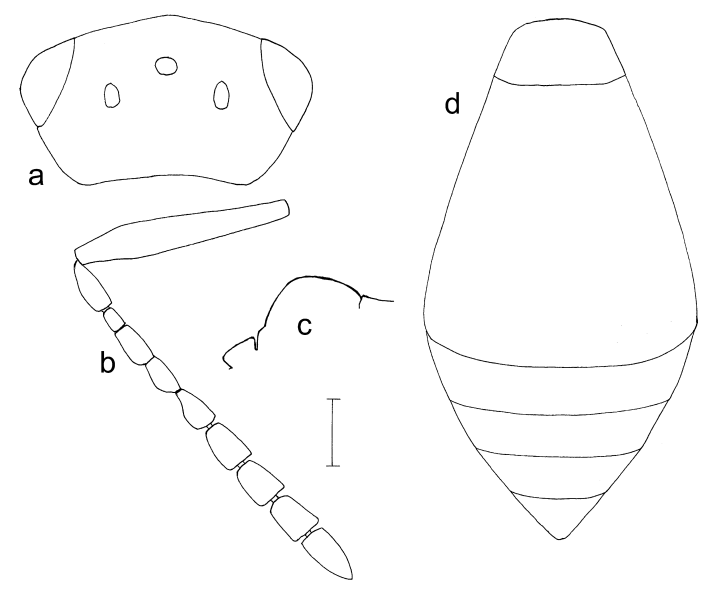

Fig. 4. Platygaster koponeni sp. n., female. - a. Head from above. - b. Antenna. - c. Scutellum and propodeum. - d. Metasoma from above. Scale bar $=$ $0.10 \mathrm{~mm}$

Diagnosis. A dark species with strongly striated occiput, sculptured frons, and with preapical antennal segments slightly longer than wide; notauli and striation of T2 almost absent; metasoma short.

Description (female). Body length $1.6 \mathrm{~mm}$. Colour black, antennae hardly lighter except dark brown A2-A3; legs dark brownish except trochanters, both ends of tibiae, and segments 14 of tarsi which are light brown.

Head from above (Fig. 4a) 1.8 times as wide as long, hardly 1.1 times as wide as thorax; occiput rounded, strongly transversely striated all over; vertex finely reticulate-coriaceous, between and in front of ocelli with transverse striations; frons with a smooth raised longitudinal line medially, finely fan-like striated, just above antennae more transversely striated. OOL and LOL equal. Head in frontal view about 1.15 times as wide as high, antenna (Fig. 4b) with A1 hardly 0.9 times as long as height of head, A9 about 1.3 times as long as wide.

Mesosoma 1.5 times as long as wide, almost 1.1 times as high as wide. Sides of pronotum finely longitudinal reticulate-coriaceous except hind margin. Mesoscutum shiny, with long and sparse hairs, in anterior half distinctly reticulate; from posterior $0.50-0.25$ with faint longitudinal sculpture on mid lobe, smooth on lateral lobes; notauli weakly indicated in extreme posterior part; mid lobe posteriorly smooth, sligthly raised and rather narrow, distinctly prolonged to base of scutellum; scuto-scutellar grooves wide and with dense whitish hairs. Mesopleuron smooth except for a few wrinkles below tegulae. Scutellum (Fig. 4c) distinctly above level of mesoscutum, almost evenly convex, hardly sculptured, with dense hairs. Metapleuron with dense greyish pilosity all over. Propodeal carinae short, dark, hardly diverging; area between them strongly transverse, shiny and almost smooth.

Fore wing fully 0.8 times as long as body, 2.5 times as long as wide, clear but rather densely hairy (almost bare in basal two-fifths); marginal cilia hardly one-tenth the width of wing. Hind wing 4.7 times as long as wide, with two frenal hooks; marginal cilia hardly one-fourth the width of wing.

Metasoma (Fig. 4d) almost as long as head and mesosoma combined (45:47), as wide as thorax. T1 strongly and evenly crenulated, bare dorsally. T2 with basal foveae deep, long and narrow, with a couple of striae at their apices reaching to about half the length of tergite; area between foveae with some striae reaching to hardly one-sixth the length of tergite. T3-T6 smooth, T3 with a few superficially implanted hairs laterally, T4-T5 each with a medially interrupted transverse row of deeply implanted hairs, T6 with a somewhat irregular transverse row of rather deeply implanted hairs.

Affinities. Hard to fit in Buhl's (1999a) key, but runs formally to Platygaster ungeri Buhl, 1999 which, however, has occiput less strongly striated, notauli longer and T2 differently sculptured than P. koponeni. Also hard to fit in Kieffer's (1926) key, but $P$. koponeni seems to differ least from the descriptions of the French $P$. cruciferarum Kieffer, 1916 and $P$. viburni Kieffer, 1916 (females and type material unknown), but these species have darkened wings, differently coloured legs, T2 not striated medially, and other details not fitting to characters of $P$. koponeni.

\section{Platygaster martikaineni sp. n. (Fig. 5)}

Type material. Holotype Q: Finland (69105:6049), Sb, Savonranta, Muhamäki 10.VIII.-4.IX.1996, P. Martikainen leg. (DABH). Window trap on 
dead aspen. Paratype ○: Denmark, Jægerspris Nordskov 25.VI.1994, P. N. Buhl leg. (ZMUC).

Diagnosis. A species with bright scape, pedicel and legs, smooth frons and slightly striated occiput, complete notauli, and short metasoma with smooth T2.

Description (female). Body length $1.1 \mathrm{~mm}$. Colour black; A1-A2 and legs reddish brown, base of $\mathrm{A} 1$, trochanters, fore and mid tibiae, base of hind tibia, and segments 1-4 of all tarsi yellowish; A3-A10 rather dark brown.

Head from above (Fig. 5a) 1.8 times as wide as long, hardly 1.1 times as wide as thorax; occiput rounded, with weak but rather dense transverse striation or wrinkles; vertex smooth except for faint reticulation around anterior ocellus; frons smooth, in lower 0.3 with transverse reticulation. OOL:LOL $=2: 3$. Head in frontal view 1.2 times as wide as high, antenna (Fig. 5b) with A1 shorter than height of head (14:15).

Mesosoma 1.4 times as long as wide, almost 1.1 times as high as wide. Sides of pronotum smooth except for reticulation in upper anterior corner. Mesoscutum smooth, midlobe reticulate in anterior half, lateral lobes with weak reticulation medially; lobes bare except for hairs along outer margins; notauli distinct, abruptly ending very shortly before anterior margin of disc, evenly converging to a rather narrow prolongation of mid lobe which reaches base of scutellum; scutoscutellar grooves not wide, with some hairs. Mesopleuron smooth. Scutellum (Fig. 5c) at level of mesoscutum, smooth and rather densely hairy. Metapleuron with sparse and long pilosity all over. Propodeal carinae low, dark, parallel, slightly curved, area between them hardly transverse, smooth and shiny.

Forewing 0.9 times as long as body, 2.4 times as long as wide, faintly yellowish, with long and rather dense hairs on disc except at extreme base; marginal cilia at their longest fully 0.1 width of wing. Hindwing 5.9 times as long as wide, with two frenal hooks; marginal cilia almost 0.4 width of wing.

Metasoma (Fig. 5d) as long as head and mesosoma combined, 0.9 times as wide as thorax. T1 shiny and bare, with six longitudinal grooves or crenulae, medially with two weak longitudinal carinae rather close together. T2 entirely smooth, with two small but rather deep basal

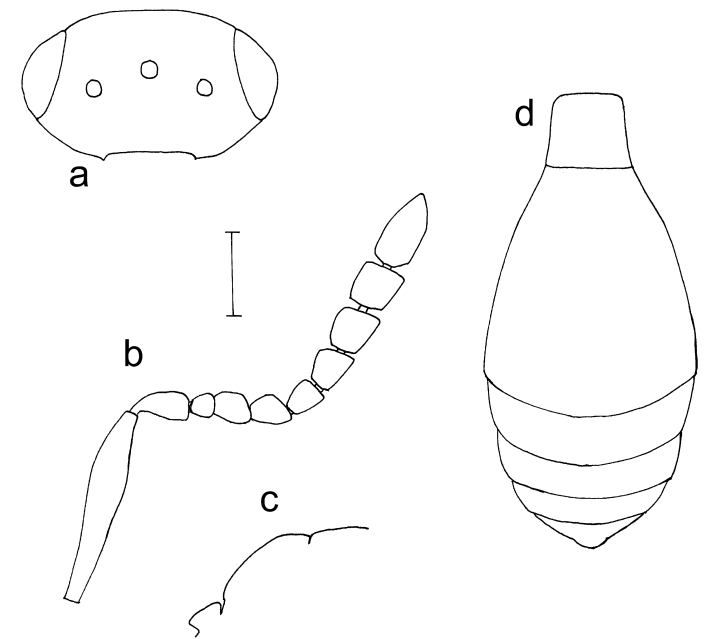

Fig. 5. Platygaster martikaineni sp. n., female. - a. Head from above. - b. Antenna. - c. Scutellum and propodeum. - d. Metasoma from above. Scale bar $=$ $0.10 \mathrm{~mm}$

foveae. T3-T6 smooth, T4-T6 each with an incomplete transverse line of superficially implanted hairs.

Affinities. Superficially similar to Platygaster nisus Walker, 1835 , but this species has very short notauli. Runs to P. oscus Walker, 1835 in Buhl's (1999a) key, but this species has head stronger sculptured than $P$. martikaineni, cf. Vlug (1985) for further separating characters. The Swedish $P$. soederlundi Buhl, 1998 differs from P. martikaineni e.g. in having darker antenna and legs, more transverse and smoother head, and smoother mesoscutum with weaker notauli, cf. Buhl (1998). $P$. martikaineni is hard to fit in Kieffer's (1926) key, but it comes closest to $P$. norvegica Kieffer, 1913 (female and type material unknown) which, however, has head smooth behind .

\section{Platygaster marttii sp. n. (Fig. 6)}

Type material. Holotype o: Finland (6822:290), St, Vammala 1.VII.1993, in shore vegetation of lake Rautavesi, M. Koponen leg. Paratype: 1 ㅇ same data. (Both in DABH).

Diagnosis. A dark species with distinctly transverse preapical antennal segments, and female metasoma twice as long as head and mesosoma combined, with tergites 3-5 sculptured and convex. 


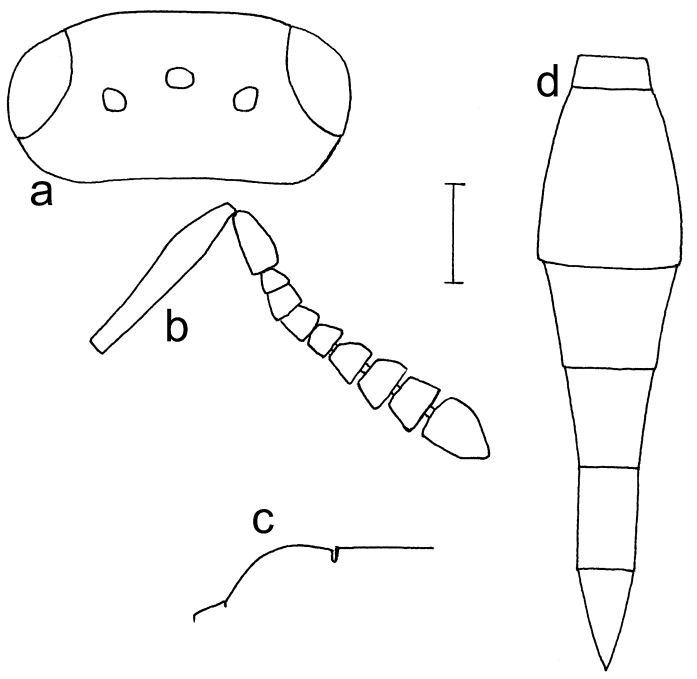

Fig. 6. Platygaster marttii sp. n., female. - a. Head from above. - b. Antenna. - c. Scutellum and propodeum. - d. Metasoma from above. Scale bar $=$ $0.10 \mathrm{~mm}(\mathrm{a}-\mathrm{c})$ and $0.20 \mathrm{~mm}(\mathrm{~d})$.

Description (female). Body length $1.8 \mathrm{~mm}$. Colour black, legs dark brown; most of fore tibia and tarsus yellowish brown.

Head from above (Fig. 6a) 2.0 times as wide as long, very slightly wider than mesosoma across tegulae. Occiput roughly transversely reticulate, with a few transverse striae. Vertex and frons distinctly reticulate-coriaceous; frons smooth medially, with transverse striae just above antennae. Lateral ocelli separated from eye by slightly more than their diameter; OOL:LOL=4:5. Head in frontal view 1.3 times as wide as high. Antenna (Fig. 6b) with A1 0.8 times as long as height of head.

Mesosoma 1.3 times as long as wide, hardly higher than wide. Sides of pronotum reticulatecoraiceous anteriorly along upper margin, rest smooth. Mesoscutum uniformly and rather distinctly longitudinally reticulate-coriaceous, almost bare. Notauli complete but shallow. Scutoscutellar grooves with very few hairs. Mesopleuron smooth. Scutellum (Fig. 6c) at level of mesoscutum, slightly but evenly convex, finely reticulate-coriaceous, sparsely hairy. Metapleuron with rather sparse greyish pilosity all over. Propodeal carinae low, very short; area between them much transverse, hardly sculptured.

Forewing reaching middle of T5, almost clear, rather densely hairy, 2.8 times as long as wide;

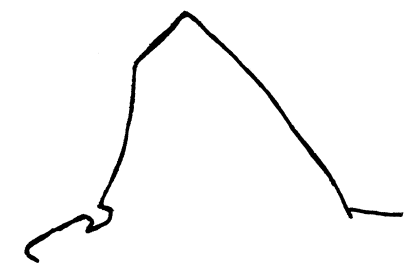

Fig. 7. Platygaster tenerifensis sp. n. female, scutellum and propodeum in lateral view. Scale bar $=0.10 \mathrm{~mm}$.

marginal cilia very short. Hindwing 5.6 times as long as wide, with two frenal hooks; marginal cilia one-fifth the width of wing.

Metasoma (Fig. 6d) twice as long as head and mesosoma combined, 0.9 times as wide as mesosoma. T1 with two strong longitudinal keels, smooth medially and laterally. T2 striated in and between basal foveae to two-fifths of length, laterally with very fine striae almost to hind margin. T3-T5 distinctly longitudinally reticulatecoriaceous all over, T3 smoother medially. T6 smooth except antero-laterally. T3-T6 with inconspicuous hairs laterally. Apical tergites rather convex, e.g. T5 medially hardly 1.9 times as wide as high, and joints between tergites thickened. Sternite 2 distinctly prolonged anteriorly.

Affinities. Most similar to $P$. tisias Walker, 1835, but this species has A9 1.1 times as wide as long, in $P$. marttii A9 is 1.5 times as wide as long, and $P$. tisias is smoother than $P$. marttii on frons and apical tergites, cf. Vlug (1985) for further separating details. $P$. marttii differs from the rather similar P. munita Walker, 1835 and $P$. oebalus Walker, 1835 e.g. in shape of antenna, metasoma and sculpture, cf. Vlug (1985).

\section{Platygaster tenerifensis Buhl, 2001 (Fig. 7)}

Material examined (119 우 $\left.130^{7}\right)$. Madeira: 1 ? Monte (550-750 m a.s.1.), 17.XII. 1994, M. Koponen leg. Canary Islands: La Palma (16 우 2 0̛): Breña Baja 27.II.-4.III.1997 (14 ㅇ 2 0̛); Los Sauces 7.IV.1998 (1 Q); National Park of Caldera de Taburiente 20.IX.1999 (1 ㅇ). Tenerife (102 우 9 ơ): Santa Ursula, La Quinta 4.XII.1992 (2 O) and 28.III.-9.IV.1993 (90 ㅇ 2 ơ); Puerto de La Cruz, Parque Taoro 19.XII.1997 (1 ơ); Mte. Aguirre (1 $q 3$ ơ) 10.XI.1985, 11.VI.1985 and 26.II.1986; Las Agras (1 O) 5.XI.1986; Mte. Los 
Silos (2 O 1 Ơ) 12.VI.1985 and 14.XII.1997; Palo Blanco (3 9 ( $\left.0^{7}\right)$ 27.VI.1984 and 29.XI.1985; Bco. Ijrana (1 O') 4.X.1984; Genores (2 O) 15.II.1985; Teno Bajo (1 \&) 22.III.1999. M. Koponen \& M. Báez. One female preserved in the Museo Nacional de Ciencias Naturales, Madrid, Spain.

Supplement to original description. About 30 percent of the females and 80 percent of the males in the new material have scutellum much raised, almost pyramid-shaped (Fig. 7), one of many examples of the striking intraspecific variation in platygastrids. No other consistent variation between specimens with this shape of scutellum and specimens with scutellum shaped as in type specimens, cf. Buhl (2001), was discovered.

Female. Length 1.20-2.25 mm. Metasoma up to fully twice as long as head and mesosoma combined.

Male (hitherto unknown). Length 1.05-1.35 $\mathrm{mm}$. Antenna with flagellar segments of equal width; A4 not widened, fully 2.5 times as long as wide, 3 times as long as A3; A5-A9 about equal, each about as long as A4 and 2.2-3.1 times as long as wide (segments more elongate in larger specimens); A10 1.5 times as long as A9; flagellar pubescence distinct, equal to width of segments. Metasoma 0.8-1.0 times as long as head and mesosoma combined.

\section{Synopeas koponeni sp. n. (Fig. 8)}

Type material. Holotype ㅇ: Canary Islands, La Palma, Breña Baja, Los Cancajos, 5.IV.1998, M. Koponen leg. (TFMC). Paratypes (4 \$): 1 \& same locality as holotype but 27.III.1998, M. Koponen leg. (DABH); Canary Islands, Tenerife, Punta de Teno, 1 9 14.XII.1997, M. Koponen leg. (DABH); Tenerife, Güimar, 2 ㅇ 19.IV.1998, E. Guerrero leg. (TFMC).

Diagnosis. Very dark species; occiput rounded; mesoscutum without notauli, behind hardly elevated, at level of scutellum; scutellum without tooth; metasoma convex, about as high as wide, T6 transverse.

Description (female). Body length $0.95 \mathrm{~mm}$. Colour black, antennae and legs dark brown, segments 1-4 of all tarsi light brown.

Head from above (Fig. 8a) 1.8 times as wide as long, 1.1 times as wide as thorax, weakly shiny,

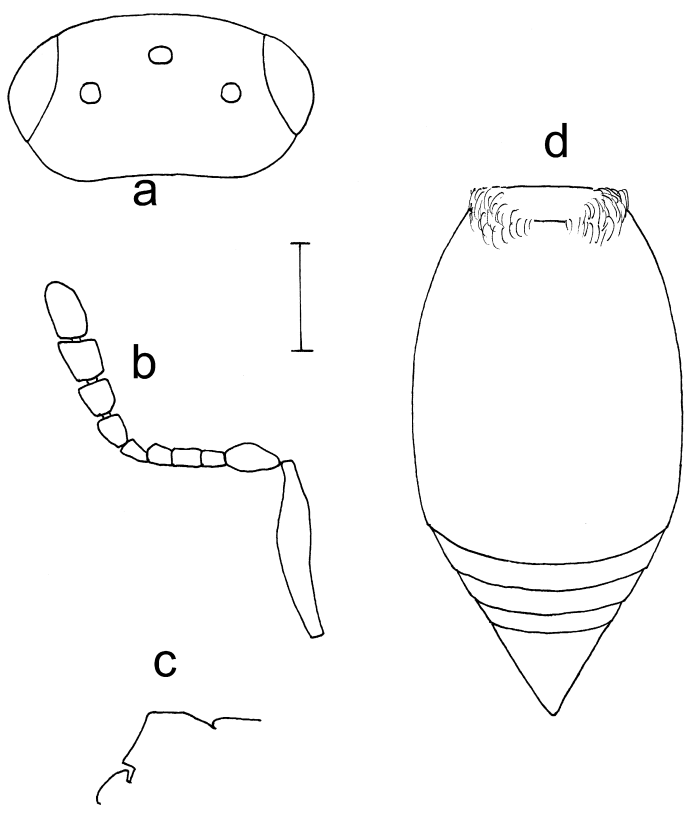

Fig. 8. Synopeas koponenisp. n., female. - a. Head from above. - b. Antenna. - c. Scutellum and propodeum. - d. Metasoma from above. Scale bar $=$ $0.10 \mathrm{~mm}$.

finely reticulate-coriaceous, transversely so above antennae and behind, occiput evenly rounded, lateral ocelli separated from eye by slightly more than their diameter. Head in frontal view 1.2 times as wide as high, antenna (Fig. 8b) with A1 0.7 times as long as height of head.

Mesosoma one and a third times as long as wide, very slightly higher than wide (16:15). Sides of pronotum dull, finely reticulate-coriaceous except along smoother hind margin. Mesoscutum faintly shiny, finely reticulate-coriaceous and with sparse hairs, notauli indicated in extreme posterior part, mid lobe behind prolonged to base of scutellum, slightly swollen, smoother and lighter than rest of disc; scuto-scutellar grooves wide, with numerous hairs. Mesopleuron smooth, at most with a few wrinkles below tegulae. Scutellum (Fig. 8c) hardly with sculpture, almost bare dorsally, rather densely hairy laterally, without tooth or lamella behind. Metapleuron smooth and bare above and in anterior two-fifths, rest with dense whitish pilosity. Propodeal carinae close together, slightly diverging, low, dark, a little curved.

Forewing 0.8 times as long as body, distinctly overreaching tip of metasoma, 2.4 times as long as 


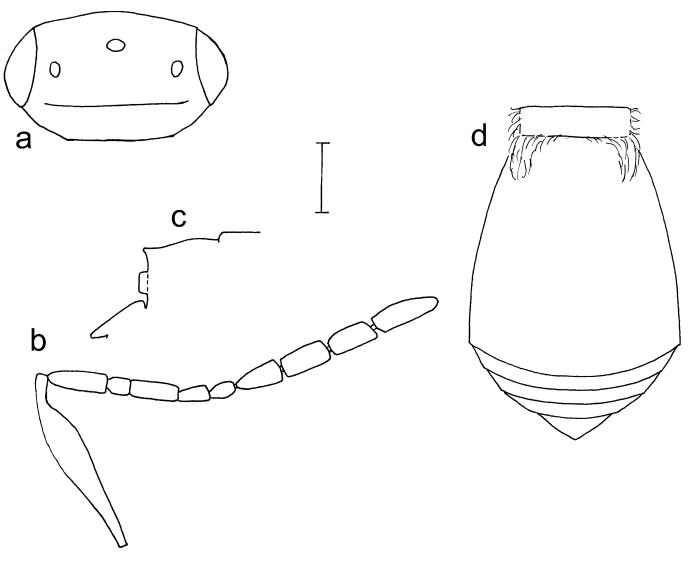

Fig. 9. Synopeas suomiana sp. n., female. - a. Head from above. - b. Antenna. - c. Scutellum and propodeum. - d. Metasoma from above. Scale bar $=$ $0.10 \mathrm{~mm}$

wide, clear and moderately hairy, without marginal cilia. Hind wing 5.6 times as long as wide, length of marginal cilia about two-fifths the width of wing.

Metasoma (Fig. 8d) about as long as head and mesosoma combined (1.4 times as long as mesosoma), about as wide as thorax, hardly as high as wide $(14: 15)$. Tergites almost smooth, hind margin of T2 and apical tergites with weak microsculpture, T3-T6 with a few superficially implanted hairs, T6 weakly reticulate. Sternites sculptured correspondingly to tergites, but sculpture slightly more distinct.

Affinities. Runs to S. hyllus (Walker, 1835) in Vlug's (1985) key, but this species has metasoma 1.3 times as high as wide, 1.8 times as long as mesosoma. S. koponeni differs also from this species, as well as from $S$. salicicola (Kieffer, 1913), in having antennal club less sharply differentiated (A7 and A8 intermediate in size of surrounding segments). In shape of antennal club also much different from $S$. daucicola Kieffer, 1916. Cf. Kieffer (1926) and Vlug (1985).

\section{Synopeas suomiana sp. n. (Fig. 9)}

Type material. Holotype O: Finland (6715:375), N, Nurmijärvi 30.VIII.1992, in a swamp, M. Koponen leg. (DABH).

Diagnosis. Belongs to Synopeas s. str.; preapical antennal segments of female twice as long as wide, mesoscutum without trace of notauli, scutellum with small tooth, fore wings with short marginal cilia; metasoma short, not particularly convex, tergite 6 much transverse.

Description (female). Body length $1.1 \mathrm{~mm}$. Colour black; A1-A6, mandibles and legs rather uniformly yellowish red; A7-A10 dark brown.

Head from above (Fig. 9a) 1.7 times as wide as long, as wide as mesosoma across tegulae, dull, finely and uniformly reticulate-coriaceous, with a moderately strong and almost complete occipital carina. OOL:LOL = 1:4; lateral ocelli separated from eye by their diameter. Head in frontal view 1.1 times as wide as high. Antenna (Fig. 9b) with A1 almost as long as height of head (16:17).

Mesosoma 1.4 times as long as wide, 1.1 times as high as wide. Sides of pronotum smooth along hind margin and on lower half, rest distinctly reticulate-coriaceous. Mesoscutum finely but distinctly and uniformly reticulate-coriaceous, with sparse hairs, without notauli; hind margin slightly prolonged medially, not swollen; scuto-scutellar grooves with very few hairs. Mesopleuron smooth. Scutellum (Fig. 9c) smooth and laterally with rather dense hairs, not keeled, posteriorly with a very small tooth and with a distinct, semitransparent lamella. Metapleuron with long and rather sparse pilosity, in anterior 0.3 smooth and bare. Propodeal carinae fused, high and semitransparent.

Forewing almost 1.1 times as long as body, 2.6 times as long as wide, densely hairy and with faint yellowish tint; marginal cilia very short. Hindwing 6.0 times as long as wide; marginal cilia 0.4 width of wing.

Metasoma (Fig. 9d) shorter than mesosoma (27:29) and hardly as wide as this, 1.4 times as wide as high. Tergites smooth except for reticulate-coriaceous hind margins. T6 reticulatecoriaceous all over.

Affinities. A most distinct species on account of elongate A7-A9. Runs to $S$. gallicola Kieffer, 1916 in Kieffer's (1926) key and to S. brevis Buhl, 1998 and S. bohemani Buhl, 1998 in Buhl's (1999a) key, but these species have A7-A9 at most as long as wide (and differ from S. suomiana in certain other characters as well).

Acknowledgements. I am very grateful to Martti Koponen, Department of Applied Biology, University of Helsinki, and Marcos Báez, University of La Laguna, for placing material at my disposal. 


\section{References}

Buhl, P. N. 1998: On some new or little known NW European species of Platygastridae (Hymenoptera, Proctotrupoidea). - Fragmenta Ent. 30: 295-334.

Buhl, P. N. 1999a: A synopsis of the Platygastridae of Fennoscandia and Denmark (Hymenoptera, Platygastroidea). - Entomofauna 20: 17-52.

Buhl, P. N. 1999b: Platygastridae (Hymenoptera) species of a Juniperus thurifera L. forest of Los Monegros region (Zaragoza, Spain). — Zapateri Revta. Aragon. Ent. 8 (1998): 11-42.

Buhl, P. N. 2001: Eleven new species of Platygastrinae (Hymenoptera: Platygastridae). - Folia Ent. Hung. 62: 133-149.
Buhl, P. N. \& Koponen, M. 2003a: New records of Platygastridae (Hymenoptera: Proctotrupoidea) from Finland. - Entomol. Fennica 14: 98-104.

Buhl, P. N. \& Koponen, M. 2003b: Platygastridae from the Canary Islands and Madeira (Hymenoptera, Platygastroidea). — Entomol. Fennica 14: 109-117.

Kieffer, J. J. 1926: Hymenoptera Proctotrupoidea. Scelionidae. - In: Das Tierreich 48. Walter de Gruyter \& Co., Berlin \& Leipzig. 885 pp.

Vlug, H. J. 1985: The types of Platygastridae (Hymenoptera, Scelionoidea) described by Haliday and Walker and preserved in the National Museum of Ireland and in the British Museum (Natural History). 2. Keys to species, redescriptions, synonymy. - Tijdschr. Ent. 127: 179-224. 